\title{
Predictors of sleep disturbance in menopausal transition
}

\section{Lampio, Laura}

2016-12

Lampio , L , Saaresranta , T, Engblom , J , Polo , O \& Polo-Kantola , P 2016 , ' Predictors of

sleep disturbance in menopausal transition ', Maturitas , vol. 94 , pp. 137-142 . https://doi.org/10.1016/j.maturitas.20

http://hdl.handle.net/10138/229844

https://doi.org/10.1016/j.maturitas.2016.10.004

publishedVersion

Downloaded from Helda, University of Helsinki institutional repository.

This is an electronic reprint of the original article.

This reprint may differ from the original in pagination and typographic detail.

Please cite the original version. 


\title{
Predictors of sleep disturbance in menopausal transition
}

\author{
Laura Lampio (MD) $)^{\mathrm{a}, \mathrm{b}, *}$, Tarja Saaresranta (MD, PhD) $)^{\mathrm{a}, \mathrm{c}}$, Janne Engblom (DSc, MSc) ${ }^{\mathrm{d}}$, \\ Olli Polo (MD, PhD) $)^{\mathrm{e}}$, Päivi Polo-Kantola (MD, PhD) ${ }^{\mathrm{a}, \mathrm{f}}$
}

\footnotetext{
a Sleep Research Centre, Department of Physiology, University of Turku, Turku, Finland

b Department of Obstetrics and Gynecology, Helsinki University Hospital, Helsinki, Finland

${ }^{c}$ Division of Medicine, Department of Pulmonary Diseases, Turku University Hospital, Turku, Finland

${ }^{\mathrm{d}}$ Department of Statistics, University of Turku, Turku, Finland

e Department of Pulmonary Diseases, Tampere University Hospital, Tampere, Finland

${ }^{\mathrm{f}}$ Department of Obstetrics and Gynecology, Turku University Hospital, Turku, Finland
}

\section{A R T I C L E I N F O}

\section{Article history:}

Received 6 June 2016

Received in revised form

13 September 2016

Accepted 4 October 2016

\section{Keywords:}

Menopause

Sleep disturbances

Depressive symptoms

Night sweats

Personal crises

Perceived impaired health

CNS medication

\begin{abstract}
A B S T R A C T
Objective: This follow-up study aimed to evaluate risk factors for menopausal sleep disturbances already identifiable before menopause.

Methods: At baseline, all 81 women were premenopausal. At year-five follow-up, 27 of the women were premenopausal, 40 postmenopausal, and 14 postmenopausal and using hormone therapy. We used the Basic Nordic Sleep Questionnaire to study sleep; additional questionnaires evaluated risk factors for sleep impairment.

Results: Sleep quality differed only marginally between the groups. The following baseline variables were associated with impaired sleep quality at follow-up: depressive symptoms increased the risk of nocturnal awakenings (OR 1.16 (95\%CI 1.02-1.32), $p=0.025$ ), morning tiredness (OR 1.22 (95\%CI 1.06-1.40), $p=0.007$ ), daytime tiredness (OR $1.24(95 \% \mathrm{CI} 1.06-1.44), p=0.007)$ and propensity to fall asleep during work or leisure time (OR $1.18(95 \% \mathrm{CI} 1.01-1.37), p=0.036)$. Personal crises increased the risk of longer sleep latency (OR $5.46(95 \% \mathrm{CI} 1.13-26.32), p=0.035$ ) and of propensity to fall asleep when not active (OR 5.41 (95\%CI 1.42-20.83), $p=0.014$ ). Use of medications affecting the CNS increased the risk of worse general sleep quality (OR 11.44 (95\% CI 1.07-121.79), $p=0.044$ ). Perceived impaired general health (OR 2.87 (95\%CI 1.04-7.94), $p=0.043$ ) and frequent night sweats (OR 10.50 (95\%CI 2.25-49.01), $p=0.003$ ) increased the risk of difficulty falling asleep.

Conclusions: Various premenopausal health-related factors seem to predict poor sleep in menopausal transition. Menopause itself appears to have only minor effects. Thus, it is essential to identify highrisk women to allow timely interventions that may prevent the development of sleep disturbances at menopause.
\end{abstract}

(c) 2016 Elsevier Ireland Ltd. All rights reserved.

\section{Introduction}

Sleep disturbances result in various health problems and impaired quality of life [1-3]. Around 40-60\% of women report sleep impairment during menopause [4]. Although both menopausal transition [5-7] and aging [8] increase sleep disturbances, etiology in menopausal women is probably multifactorial. The most common menopausal complaints, nocturnal vasomotor symptoms, are associated with poor sleep [9-11]. In addition, mood symptoms, particularly depressive symptoms, are impor-

\footnotetext{
* Corresponding author at: Sleep Research Centre, University of Turku, Lemminkäisenkatu 3B, FIN-20520 Turku, Finland.

E-mail addresses: Imlamp@utu.fi, lauramaria.lampio@gmail.com (L. Lampio).
}

tant [12]. Sleep disorders, including sleep apnea [13], systemic diseases and associated medications [14], workload [15], and general stressful life events in midlife [16] might contribute to sleep disturbances. Understanding whether women's sleep disturbances during midlife are related to menopause, aging, or other causes is essential in order to provide targeted therapy.

Hormone therapy (HT) is known to alleviate subjective sleep problems in menopausal women, especially if vasomotor symptoms are present $[10,17]$. However, sleep disturbances with other etiology require alternative treatment options, such as cognitive behavioral therapy [18]. In case of depression, antidepressants may effectively alleviate also sleep disturbances [19]. Hypnotics provide short-term relief [20] but, long-term, typically deteriorate sleep quality and have other adverse consequences [21]. 
Menopausal sleep disturbances may originate from factors dating back years. Identification of such risk factors well before menopause may enable physicians to prevent development of sleep disturbances at menopause. Therefore, we aimed to evaluate changes in subjective sleep quality and study premenopausal risk factors for menopausal sleep disturbances in a prospective five-year follow-up study in midlife women. We hypothesized that indicators for menopausal sleep disturbances may be recognizable years before menopausal transition.

\section{Materials and methods}

\subsection{Study design and population}

As a part of a larger survey (Woman 46 Study) investigating sleep and cardiovascular risk in middle-aged women, participants were recruited through newspaper announcements around Turku, Finland. The main exclusion criteria included presence of coronary heart disease, respiratory insufficiency, sleep apnea, neurological disease, liver disease, malignancies, and alcohol abuse. Altogether, 147 women, aged 46 years, participated in the baseline study and were invited to the five-year follow-up. We chose the age of 46 years because the average menopause age in Finland is 51 years; thus, at follow-up, some of the women were likely to have reached menopause. Baseline data was collected from November 2001 to April 2007 and follow-up data from June 2009 to March 2012. The present follow-up study excludes 66 women: women with serum follicle stimulating hormone (S-FSH) level over $20 \mathrm{IU} / \mathrm{L}$ or using HT at baseline, those refusing to participate in the follow-up, perimenopausal women (S-FSH 20-30 IU/L) at follow-up, and women whose menopausal status could not be defined because of previous hysterectomy and missing S-FSH value. Thus, 81 women were accepted for the present study (Fig. 1). At follow-up, nine women completed questionnaires but their S-FSH and body mass index (BMI) measurements were missing.

At the five-year follow-up, women were divided into premenopausal and postmenopausal groups. Premenopause was defined as ongoing menstruation without HT use or S-FSH level lower than $21 \mathrm{IU} / \mathrm{L}$ (measured at the beginning of the follicular phase). Postmenopause was defined as amenorrhea for over one year and the age of 51 years or more, or S-FSH over $30 \mathrm{IU} / \mathrm{L}$. In case of previous hysterectomy or use of an intrauterine hormone device (causing amenorrhea), S-FSH over $30 \mathrm{IU} / \mathrm{L}$ was required. The postmenopausal group was further divided into two sub-groups based on HT use. Of the 81 women, 27 were premenopausal (pre group), 40 postmenopausal HT non-users (post group), and 14 postmenopausal HT users (post $+H T$ group). In the post group, all participants were naturally menopausal, but in the post + HT group, one participant was surgically menopausal; the rest were naturally menopausal. All participants were Caucasian. The study was approved by the Ethics Committee of the Hospital District of Southwest Finland. Written informed consent was obtained from all participants.

\subsection{Inventories}

The validated Basic Nordic Sleep Questionnaire (BNSQ) [22], focusing on subjective sleep during the three preceding months, was administered to evaluate sleep quality. The variables of the BNSQ were categorical, with low scores referring to better sleep quality or low levels of sleep problems. The alternative responses for each question were dichotomized. Sleep problems were indicated if the criteria as defined in parentheses were fulfilled: 1) general sleep quality (seldom or never good), 2) difficulties falling asleep ( $\geq 1$ night per week), 3) sleep latency ( $>20 \mathrm{~min}$ ), 4) noctur- nal awakenings ( $\geq 2$ times per night), 5 ) restless sleep (quite or very restless sleep), 6) snoring ( $\geq 1$ night per week), 7) witnessed apnea ( $\geq 1$ night per week), 8) morning headaches ( $\geq 1$ time per week), 9) morning tiredness ( $\geq 1$ time per week), 10) daytime tiredness ( $\geq 1$ time per week), 11) unintentional falling asleep during work or leisure time ( $\geq 1$ time per week), 12) unintentional falling asleep when not active (e.g. watching TV) (sometimes or more frequently), 13) naps during the day ( $\geq 1$ time per week), 14) use of sleep medication ( $\geq 1$ time per week).

We assessed vasomotor symptoms using two questions: "During the past six months, have you suffered from 1) night sweats or 2) hot flashes?" In both questions, severity of symptoms was ranked 1-4 (1: seldom or never; 2 : once a month; 3 : once a week; 4 : almost daily). Presence of current depressive symptoms was determined using the 21-item Beck Depression Inventory (BDI) [23], wherein higher scores indicate more severe depressive symptoms. Quality of life $(\mathrm{QoL})$ was defined as a single question on general satisfaction of QoL (1: very satisfied, 2: quite satisfied, 3: moderate, 4: quite unsatisfied, 5: unsatisfied, 6: very unsatisfied). Perceived general health (1: very good, 2: quite good, 3: tolerable, 4: quite bad, 5: very bad) and perceived mental health (1: very good, 2 : quite good, 3: quite bad, 4: very bad) were self-assessed. Personal crises (10 items, e.g. death or severe illness of spouse or close relative, financial difficulties, divorce) were reported as 1) no; 2) yes, within the preceding year; 3 ) yes, earlier. Participant response reporting one or more crisis within the preceding year was regarded as positive. Answers "no" and "yes, earlier" were regarded as negative. Education was graded to 1) lower (elementary school to middle school), or 2) higher (middle school + college level training to academic education). Working status was classified as 1) working, 2) retired, or 3) unemployed, and work schedule as 1) regular daytime work, 2) shift work, or 3) part-time work. Smoking (1: not at all, 2: occasionally, 3: daily, 4: over ten cigarettes per day), alcohol consumption (1: not at all, 2: 0-6 doses per week, 3: 7-14 doses per week, 4 : over 14 doses per week) and physical activity ( 1 : less than once a week, 2: 1-2 times per week, 3: over 2 times per week) were defined. Participants were asked to enumerate all used medications, among which researchers defined medications with central nervous system (CNS) effects. Participants completed the same questionnaires in an attendance of a study nurse at baseline and five-year follow-up. Height and weight were measured by the study nurse at baseline and follow-up, and BMI was calculated.

\subsection{Statistical analyses}

We used chi-square tests to compare group differences among sleep variables (dependent variables, BNSQ) separately at two time points. Of independent variables, night sweats and hot flashes, self-assessment of QoL, perceived physical health, perceived mental health, personal crises, working status, work schedule, marital status, education, alcohol consumption, smoking, physical activity, and the use of CNS medication were studied with chi-square tests, and analysis of variance (ANOVA) was used to determine group differences in the BDI total score, age, and S-FSH.

First, we conducted a univariate ANOVA analysis for each menopausal group and each independent variable with sleep variables separately at baseline and at follow-up (data not shown). Second, we conducted a multivariate analysis using a binary logistic regression model with backward selection to analyze group and time effects together with interactions adjusted for other independent variables, which remained significant in the analysis (BDI total score, night sweats, perceived general health, personal crises, use of CNS medication, and BMI). Of vasomotor symptoms, we chose night sweats over hot flashes because we have previously shown that night sweats more strongly impact sleep deterioration [9]. Night sweats were dichotomized for multivariate analyses by combining 


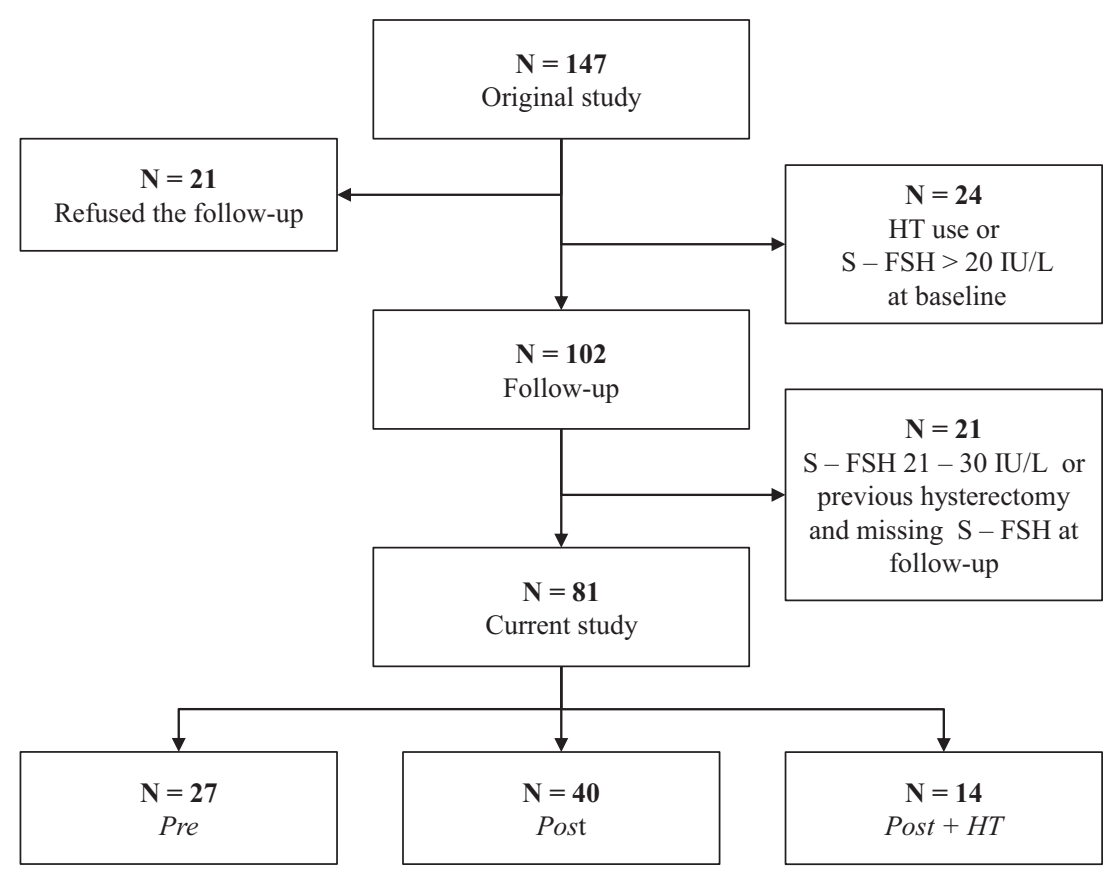

Fig. 1. Flow chart of the study. HT, hormone therapy; S-FSH, serum follicle stimulating hormone; IU/L, international units/l.

1) almost daily and once a week, or 2) once a month and seldom or never. Because of joint distribution characteristics, it was not possible to conduct multivariate analyses for four variables (restless sleep, morning headache, falling asleep during work or leisure time, use of sleep medication).

Third, we studied the effects of predisposing factors at baseline on sleep variables at five-year follow-up using multivariate analysis with binary logistic regression. We examined the effects of significant independent variables using stepwise selection. Fourth, the effects of changes (deltas) in independent variables from baseline to five-year follow-up on sleep variables were studied using a similar approach. The analyses studying predisposing factors were explorative. P-values $<0.05$ were considered statistically significant. Odds ratios (ORs) were calculated and reported with 95\% confidence intervals $(\mathrm{CI})$. Statistical analyses were carried out using SAS System for Windows, versions 9.1 and 9.3 (SAS Institute, Cary, NC).

\section{Results}

\subsection{Characteristics}

In the pre group, $3.7 \%$ were single, $81.5 \%$ married, $11.1 \%$ divorced, and $3.7 \%$ widowed. In the post group, the figures were $7.5 \%, 70.0 \%$, $20.0 \%$, and $2.5 \%$, and in the post + HT group, $7.1 \%, 85.7 \%, 7.1 \%$, and $0 \%$, respectively. For education, of the pre group, $26.3 \%$ had lower and $73.7 \%$ had higher education. In the post group, the figures were $7.1 \%$ and $82.9 \%$ and in the post $+H T$ group, $11.1 \%$ and $88.9 \%$, respectively.

\subsection{Independent variables}

At baseline, the pre, post, and post $+H T$ groups were similar $(p<0.05)$ regarding age, $\mathrm{S}-\mathrm{FSH}, \mathrm{BMI}$, BDI total score, night sweats and hot flashes, working status, work schedule, QoL, perceived general health, perceived mental health, personal crises, use of CNS medication, smoking, alcohol consumption, and physical activity. At follow-up, group characteristics were similar with the exception of S-FSH and night sweats and hot flashes: S-FSH values were higher and night sweats and hot flashes more frequent in the post and post $+H T$ groups compared to the pre group (Table 1). Four women at baseline and 13 women at follow-up used CNS medication. Antidepressants were $45 \%$ of the used medication; the rest were prescribed for chronic pain, inter alia.

\subsection{Sleep variables}

At baseline, sleep variables did not differ between groups. At follow-up, difficulty falling asleep was more frequent in the post group and less frequent in the post $+H T$ group. Morning headache was more frequent in the post group and less frequent in the pre group. General sleep quality tended to be worse and nocturnal awakenings more frequent in the post group (Table 2).

\subsection{Multivariate analyses and predisposing factors}

In multivariate analysis, there was a group effect only in one sleep variable: the post group showed increased risk for difficulty falling asleep compared to the post $+H T$ group (OR 14.58 (95\% CI 1.36-156.36), $p=0.027$ ). In the sleep variables, no other group and time interactions were found. Various independent variables at baseline had an impact on sleep at follow-up. Women with once-a-week night sweats compared to seldom or never at baseline had increased risk for difficulty falling asleep at follow-up (OR 10.50 (95\% CI 2.25-49.01), $p=0.003$ ). Those with higher BDI total score at baseline had increased risk for nocturnal awakenings (OR 1.16 (95\% CI 1.02-1.32), $p=0.025$ ), morning tiredness (OR 1.22 (95\% CI 1.06-1.40), $p=0.007)$, daytime tiredness (OR 1.24 (95\% CI 1.06-1.44), $p=0.007$ ), and falling asleep during work or leisure time (OR 1.18 (95\% CI 1.01-1.37), $p=0.036$ ) at follow-up. Women using CNS medication at baseline had increased risk for worse general sleep quality (OR 11.44 (95\% CI 1.07-121.79), $p=0.044$ ) at followup. Women with personal crises at baseline had increased risk for longer sleep latency (OR 5.46 (95\% CI 1.13-26.32), $p=0.035$ ) and falling asleep when not active (OR 5.41 (95\% CI 1.42-20.83), $p=0.014)$ at follow-up. Those perceiving their general health as tolerable/worse at baseline had increased risk for difficulty falling asleep (OR 2.87 (95\% CI 1.04-7.94), $p=0.043$ ) at follow-up. 
Table 1

Group characteristics at baseline and at follow-up, expressed as means (SD) or percentages.

\begin{tabular}{|c|c|c|c|c|c|c|c|c|}
\hline & \multicolumn{4}{|l|}{ Baseline } & \multicolumn{4}{|l|}{ Follow-up } \\
\hline & $\begin{array}{l}\text { pre } \\
\mathrm{N}=27\end{array}$ & $\begin{array}{l}\text { post } \\
\mathrm{N}=40\end{array}$ & $\begin{array}{l}\text { post }+H T \\
\mathrm{~N}=14\end{array}$ & $P$ & $\begin{array}{l}\text { pre } \\
\mathrm{N}=27\end{array}$ & $\begin{array}{l}\text { post } \\
\mathrm{N}=40\end{array}$ & $\begin{array}{l}\text { post }+H T \\
\mathrm{~N}=14\end{array}$ & $P$ \\
\hline Age (years) & $45.9(1.0)$ & $46.1(0.8)$ & $45.9(0.9)$ & 0.676 & $51.7(1.0)$ & $52.3(1.3)$ & $52.5(1.9)$ & 0.097 \\
\hline $\mathrm{FSH}(\mathrm{IU} / \mathrm{L})$ & $6.8(3.6)$ & $7.9(4.0)$ & $9.1(3.4)$ & 0.184 & $9.0(4.8)$ & $69.4(25.5)$ & $64.2(27.2)$ & $<0.001$ \\
\hline BMI (kg/m2) & $25.4(5.2)$ & $26.6(5.8)$ & $24.4(2.7)$ & 0.365 & $26.3(5.8)$ & $28.3(6.1)$ & $25.8(2.6)$ & 0.265 \\
\hline Night sweats & & & & 0.750 & & & & 0.003 \\
\hline almost daily & $3.7 \%$ & $2.6 \%$ & $0.0 \%$ & & $0.0 \%$ & $35.0 \%$ & $21.4 \%$ & \\
\hline once a week & $14.8 \%$ & $7.7 \%$ & $21.4 \%$ & & $11.1 \%$ & $20.0 \%$ & $35.7 \%$ & \\
\hline once a month & $14.8 \%$ & $20.5 \%$ & $7.1 \%$ & & $25.9 \%$ & $15.0 \%$ & $0.0 \%$ & \\
\hline seldom or never & $66.7 \%$ & $69.2 \%$ & $71.4 \%$ & & $63.0 \%$ & $30.0 \%$ & $42.9 \%$ & \\
\hline Hot flashes & & & & 0.478 & & & & 0.001 \\
\hline almost daily & $0.0 \%$ & $0.0 \%$ & $0.0 \%$ & & $0.0 \%$ & $35.9 \%$ & $7.1 \%$ & \\
\hline once a week & $0.0 \%$ & $2.6 \%$ & $0.0 \%$ & & $7.4 \%$ & $18.0 \%$ & $28.6 \%$ & \\
\hline once a moth & $7.4 \%$ & $2.6 \%$ & $14.3 \%$ & & $3.7 \%$ & $7.7 \%$ & $7.1 \%$ & \\
\hline seldom or never & $92.6 \%$ & $94.9 \%$ & $85.7 \%$ & & $88.9 \%$ & $38.5 \%$ & $57.1 \%$ & \\
\hline BDI total score & $4.2(2.5)$ & $5.6(4.6)$ & $4.0(3.9)$ & 0.244 & $4.9(4.5)$ & $7.2(6.9)$ & $4.7(3.9)$ & 0.182 \\
\hline Quality of life & & & & 0.628 & & & & 0.106 \\
\hline very or quite satisfied & $96.3 \%$ & $87.5 \%$ & $92.9 \%$ & & $96.3 \%$ & $87.5 \%$ & $85.1 \%$ & \\
\hline moderate & $3.7 \%$ & $7.5 \%$ & $7.1 \%$ & & $3.7 \%$ & $10.0 \%$ & $0.0 \%$ & \\
\hline quite or very unsatisfied & $0.0 \%$ & $5.0 \%$ & $0.0 \%$ & & $0.0 \%$ & $2.5 \%$ & $14.3 \%$ & \\
\hline Perceived general health & & & & 0.524 & & & & 0.379 \\
\hline very or quite good & $63.0 \%$ & $62.5 \%$ & $78.6 \%$ & & $69.2 \%$ & $55.0 \%$ & $71.4 \%$ & \\
\hline tolerable or worse & $37.0 \%$ & $37.5 \%$ & $21.4 \%$ & & $30.8 \%$ & $45.0 \%$ & $28.6 \%$ & \\
\hline Perceived mental health & & & & 0.441 & & & & 0.579 \\
\hline very good & $74.1 \%$ & $57.5 \%$ & $50.0 \%$ & & $52.0 \%$ & $43.6 \%$ & $42.9 \%$ & \\
\hline quite good & $25.9 \%$ & $40.0 \%$ & $50.0 \%$ & & $44.0 \%$ & $51.3 \%$ & $57.1 \%$ & \\
\hline quite bad & $0.0 \%$ & $2.5 \%$ & $0.0 \%$ & & $0.0 \%$ & $5.1 \%$ & $0.0 \%$ & \\
\hline very bad & $0.0 \%$ & $0.0 \%$ & $0.0 \%$ & & $4.0 \%$ & $0.0 \%$ & $0.0 \%$ & \\
\hline Personal crises during the past year & $51.9 \%$ & $72.5 \%$ & $64.3 \%$ & 0.224 & $66.7 \%$ & $70.0 \%$ & $57.1 \%$ & 0.680 \\
\hline Working status & & & & 0.155 & & & & 0.451 \\
\hline working & $100.0 \%$ & $85.0 \%$ & $92.9 \%$ & & $92.6 \%$ & $89.7 \%$ & $92.3 \%$ & \\
\hline retired & $0.0 \%$ & $2.5 \%$ & $0.0 \%$ & & $0.0 \%$ & $7.7 \%$ & $7.1 \%$ & \\
\hline unemployed & $0.0 \%$ & $12.5 \%$ & $0.0 \%$ & & $7.4 \%$ & $2.5 \%$ & $0.0 \%$ & \\
\hline Work schedule & & & & 0.410 & & & & 0.392 \\
\hline regular daytime work & $74.1 \%$ & $79.4 \%$ & $76.9 \%$ & & $73.1 \%$ & $83.8 \%$ & $61.5 \%$ & \\
\hline shift work & $14.8 \%$ & $20.6 \%$ & $15.4 \%$ & & $19.3 \%$ & $8.1 \%$ & $30.8 \%$ & \\
\hline part-time work & $11.1 \%$ & $0.0 \%$ & $7.7 \%$ & & $7.7 \%$ & $8.1 \%$ & $7.7 \%$ & \\
\hline Daily smoking & $3.7 \%$ & $7.5 \%$ & $0.0 \%$ & 0.926 & $3.9 \%$ & $7.5 \%$ & $0.0 \%$ & 0.338 \\
\hline Alcohol consumption & & & & 0.586 & & & & 0.661 \\
\hline not at all & $7.4 \%$ & $20.0 \%$ & $15.4 \%$ & & $14.8 \%$ & $22.5 \%$ & $28.6 \%$ & \\
\hline 0-6 doses a week & $81.5 \%$ & $65.0 \%$ & $76.9 \%$ & & $74.1 \%$ & $60.0 \%$ & $64.3 \%$ & \\
\hline 7-14 doses a week & $11.1 \%$ & $15.0 \%$ & $7.7 \%$ & & $11.1 \%$ & $17.5 \%$ & $7.1 \%$ & \\
\hline over 14 doses a week & $0.0 \%$ & $0.0 \%$ & $0.0 \%$ & & $0.0 \%$ & $0.0 \%$ & $0.0 \%$ & \\
\hline Physical activity & & & & 0.171 & & & & 0.795 \\
\hline less than once a week & $3.7 \%$ & $5.0 \%$ & $14.3 \%$ & & $11.5 \%$ & $10.0 \%$ & $7.1 \%$ & \\
\hline 1-2 times a week & $48.2 \%$ & $25.0 \%$ & $21.4 \%$ & & $26.9 \%$ & $40.0 \%$ & $28.6 \%$ & \\
\hline$\geq 3$ times a week & $48.2 \%$ & $70.0 \%$ & $64.3 \%$ & & $61.5 \%$ & $50.0 \%$ & $64.3 \%$ & \\
\hline Use of CNS affecting medication & $0.0 \%$ & $10.0 \%$ & $0.0 \%$ & 0.116 & $11.1 \%$ & $20.0 \%$ & $14.3 \%$ & 0.611 \\
\hline
\end{tabular}

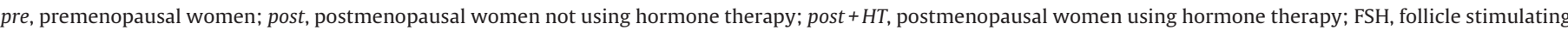
hormone; IU/L, international units/liter; BMI, body mass index; BDI, Beck Depression Inventory; CNS, central nervous system.

Table 2

Results of the Basic Nordic Sleep Questionnaire at baseline and at follow-up, expressed as percentages.

\begin{tabular}{|c|c|c|c|c|c|c|c|c|}
\hline & \multicolumn{4}{|c|}{ Baseline } & \multicolumn{4}{|c|}{ Follow-up } \\
\hline & $\begin{array}{l}\text { pre } \\
N=27\end{array}$ & $\begin{array}{l}\text { post } \\
\mathrm{N}=40\end{array}$ & $\begin{array}{l}\text { post }+H T \\
\mathrm{~N}=14\end{array}$ & $P$ & $\begin{array}{l}\text { pre } \\
\mathrm{N}=27\end{array}$ & $\begin{array}{l}\text { post } \\
N=40\end{array}$ & $\begin{array}{l}\text { post }+H T \\
\mathrm{~N}=14\end{array}$ & $P$ \\
\hline General sleep quality seldom or never good & $11.1 \%$ & $25.0 \%$ & $15.4 \%$ & 0.340 & $11.1 \%$ & $35.0 \%$ & $14.3 \%$ & 0.052 \\
\hline Difficulties falling asleep $\geq 1$ night per week & $25.9 \%$ & $32.5 \%$ & 7.7.\% & 0.210 & $18.5 \%$ & $42.5 \%$ & $7.1 \%$ & 0.016 \\
\hline Sleep latency over $20 \mathrm{~min}$ & $30.8 \%$ & $35.9 \%$ & $7.7 \%$ & 0.153 & $14.8 \%$ & $30.0 \%$ & $7.1 \%$ & 0.123 \\
\hline Nocturnal awakenings $\geq 2$ times per night & $37.0 \%$ & $50.0 \%$ & $46.2 \%$ & 0.576 & $25.9 \%$ & $55.0 \%$ & $35.7 \%$ & 0.053 \\
\hline Restless sleep & $25.9 \%$ & $25.0 \%$ & $0.0 \%$ & 0.143 & $18.5 \%$ & $41.0 \%$ & $28.6 \%$ & 0.148 \\
\hline Snoring $\geq 1$ night per week & $37.0 \%$ & $33.3 \%$ & $38.5 \%$ & 0.924 & $42.3 \%$ & $48.7 \%$ & $46.1 \%$ & 0.879 \\
\hline Witnessed apneas $\geq 1$ night per week & $0.0 \%$ & $5.3 \%$ & $7.7 \%$ & 0.418 & $4.0 \%$ & $7.9 \%$ & $0.0 \%$ & 0.514 \\
\hline Morning headache $\geq 1$ time per week & $7.4 \%$ & $12.5 \%$ & $7.7 \%$ & 0.757 & $0.0 \%$ & $20.0 \%$ & $7.1 \%$ & 0.033 \\
\hline Morning tiredness $\geq 1$ time per week & $51.9 \%$ & $52.5 \%$ & $15.4 \%$ & 0.051 & $44.4 \%$ & $60.0 \%$ & $35.7 \%$ & 0.216 \\
\hline Daytime tiredness $\geq 1$ time per week & $63.0 \%$ & $52.5 \%$ & $46.2 \%$ & 0.548 & $55.6 \%$ & $62.5 \%$ & $57.1 \%$ & 0.838 \\
\hline Falling asleep during work or leisure time $\geq 1$ time/week & $14.8 \%$ & $5.0 \%$ & $0.0 \%$ & 0.174 & $11.1 \%$ & $22.5 \%$ & $14.3 \%$ & 0.898 \\
\hline Falling asleep when not active sometimes or often & $37.0 \%$ & $22.5 \%$ & $23.1 \%$ & 0.394 & $18.5 \%$ & $30.0 \%$ & $42.9 \%$ & 0.248 \\
\hline Naps $\geq 1$ time per week & $33.3 \%$ & $42.5 \%$ & $30.8 \%$ & 0.645 & $40.7 \%$ & $27.5 \%$ & $28.6 \%$ & 0.498 \\
\hline Use of sleep medication $\geq 1$ time per week & $0.0 \%$ & $10.0 \%$ & $0.0 \%$ & 0.122 & $7.4 \%$ & $12.5 \%$ & $0.0 \%$ & 0.345 \\
\hline
\end{tabular}

pre, premenopausal women; post, postmenopausal women not using hormone therapy; post + HT, postmenopausal women using hormone therapy. 
Women whose frequency of night sweats increased from baseline to follow-up compared to women with no change had increased risk for worse general sleep quality (OR 4.95 (95\% CI 1.41-17.39), $p=0.013$ ), difficulty falling asleep (OR 9.60 (95\% CI 2.44-37.78), $p=0.002$ ), nocturnal awakenings (OR $5.24(95 \% \mathrm{CI}$ $1.89-14.49), p=0.002$ ), restless sleep (OR 4.27 (95\% CI 1.41-12.94), $p=0.011$ ), and daytime tiredness (OR 3.88 (95\% CI 1.43-10.56), $p=0.009$ ) at follow-up. Women whose frequency of night sweats decreased had increased risk for difficulty falling asleep compared to those with no change in the frequency of night sweats (OR 25.0 (95\% CI 2.94-100.00), $p=0.004$ ). Those with increasing BMI during the follow-up period had increased risk for snoring (OR 1.38 (95\% CI 1.02-1.87), $p=0.039$ ) at follow-up. Women with increased alcohol consumption during the follow-up period had increased risk for use of sleep medication (OR 10.83 (95\% CI 1.73-67.81), $p=0.012$ ) at follow-up.

\section{Discussion}

Identifying premenopausal women at risk for developing sleep disturbances during menopausal transition is essential in preventing the manifestation of sleep disturbances. Based on our results, some indicators for sleep disturbances at postmenopause are already evident before menopausal hormonal changes are detected. These indicators include frequent night sweats, depressive symptoms, use of CNS medication, occurrence of personal crises, and unsatisfactory perceived health. HT benefited sleep quality.

We found that menopause itself was not critical for sleep impairment. Instead, vasomotor symptoms, which increased markedly in women entering postmenopause, and depressive symptoms were the most important risk factors for impaired sleep quality. Menopausal transition has been documented as an important hallmark for increased risk for sleep disturbances [5-7]. Furthermore, concurrent vasomotor symptoms add to the risk [9-11,24]. Thus, the existence of vasomotor symptoms might differentiate the distinct menopausal phenotypes, and hence identify those at risk for developing sleep disturbances. In our study, decreasing frequency of night sweats also increased the risk for difficulty falling asleep for no evident reason. Vasomotor symptoms are effectively treated with HT [25]. This explains why sleep disturbances in women using HT were not more frequent compared to premenopausal women in our study. Thus, as previously suggested [17,26,27], HT seems to have a place in the treatment of menopausal sleep disturbances.

The literature is consistent that depressive symptoms are often accompanied by sleep problems [28,29]; the association has also been documented in perimenopausal and postmenopausal women [30]. Based on our results, the influence of depressive symptoms on sleep showed to be rather persistent. The pathophysiology behind the relationship between depressive symptoms and sleep disturbances is not well understood, but it has been concluded that sleep difficulty is a prodromal symptom for depression, and reciprocally, depressed individuals appear to have increased risk for sleep disturbances [29]. In our study, use of CNS medication at baseline predisposed women to menopausal sleep disturbances. This was probably associated with depressive mood, as the most used CNS medications were antidepressants. However, a part of CNS medication was prescribed for chronic pain. Chronic pain is universally associated with disrupted sleep [14]. Perceived impaired general health at baseline predicted menopausal sleep disturbances. We have previously shown in middle-aged female population that perception of both physical and mental health is the most important contributor for sleep problems, to an even greater extent than the existence of chronic diseases or use of medications [31]. These results support the current view that sleep disturbances are more often comorbid than primary [29,32].
The finding that increased alcohol consumption during the follow-up period increased the risk for use of sleep medication could be explained in at least two ways. Use of alcohol may worsen sleep quality, leading to the need for sleep medication. The wellknown U-shaped association between alcohol consumption and sleep quality [33] has been confirmed previously in middle-aged female population [31]. We can also speculate that women in our study used alcohol as a sleep aid. As it presumably was ineffective, these women sought help from sleep medication.

Menopausal transition takes place at midlife, often coinciding with various life stressors. Personal crises, such as marital problems, empty nest syndrome, loss of significant others, and growing demands at work, might contribute to sleep disturbances [16]. According to our study, crises seem to have persisting effects on sleep. Recently, it has been demonstrated that individual's vulnerability to stress-related transient sleep disturbances may be a predisposing factor for long-term insomnia [34], and especially stressful family events may predict insomnia [35]. Alternatively, sleep in menopausal women might generally be sensitive to situational stressors; insomnia symptoms might recur when those stressors are encountered. We have shown this previously in terms of work stress [15]. In the light of these previous studies and the present results, early intervention is crucial to prevent sleep disturbances during and after menopause.

The major strength of our study is the prospective five-year follow-up design, which allowed us to evaluate changes in both sleep quality and several factors contributing to sleep during menopausal transition. Furthermore, the studied groups were very homogenous in terms of demographic factors. It is known that culture, ethnicity, or both might affect the severity of sleep disturbances at various menopausal stages [36]. Our cohort consisted of relatively healthy Finnish women. Thus, it was more unambiguous to study the effects of menopause itself on sleep. The risk factors we evaluated are routinely addressed when interviewing patients with sleep complaints and therefore feasible for everyday clinical practice.

Our study had some limitations. First, sample size was rather small and therefore results may be biased by type 2 error. The number of participants in some symptom categories was low, resulting in joint distribution characteristics, thus restricting more detailed analyses. As the impact of the most-identified risk factors (depressive symptoms, personal crises, CNS medication, perceived impaired general health, and frequent night sweats) was quite strong, our conclusions are justified. However, because of the limited sample size, results should be interpreted cautiously and reevaluated in larger cohorts of women. Second, we could not use the Stages of Reproductive Aging Workshop (STRAW) criteria [37] to define menopausal status; rather, we based the grouping on S-FSH levels, age, and menstrual history. STRAW criteria were published after the initiation of our study. Further, we studied only subjective sleep. Discrepancies between subjectively and objectively measured sleep in menopausal women are well acknowledged [38]. However, in clinical practice, sleep complaints direct diagnostics and treatment. Further, we studied the frequency but not severity of vasomotor symptoms.

\section{Conclusions}

Identifying predisposing factors for menopausal sleep disturbances in earlier midlife may enable preventive interventions for high-risk individuals. Our findings should alert primary healthcare providers and gynecologists to find women at high risk of sleep disturbances and provide adequate support and treatment already before menopause. 


\section{Contributors}

LL is the principal investigator and writer of the paper.

TS is the leader of the study, co-investigator, and co-writer.

$\mathrm{JE}$ is the statistician in the study.

$\mathrm{OP}$ and $\mathrm{PP}-\mathrm{K}$ are co-investigators and co-writers.

All authors have approved the final manuscript.

\section{Funding}

This work was supported by the Finnish Menopause Society, Finnish Sleep Research Society, Finnish Anti-Tuberculosis Association, Turku University Hospital government grant, and Turku University Foundation.

\section{Ethical approval}

The study had the approval of the Ethics Committee of the Hospital District of Southwest Finland. Written informed consent was obtained from all participants.

\section{Provenance and peer review}

This article has undergone peer review.

\section{Conflict of interest}

The authors declare that they have no conflict of interest.

\section{Acknowledgement}

We wish to thank Tero Vahlberg, MSc, for statistical assistance.

\section{References}

[1] F.P. Cappuccio, L. D’Elia, P. Strazzullo, M.A. Miller, Quantity and quality of sleep and incidence of type 2 diabetes: a systematic review and meta-analysis, Diab. Care 2 (2010) 414-420.

[2] K.L. Knutson, Sleep duration and cardiometabolic risk: a review of the epidemiologic evidence, Best Pract. Res. Clin. Endocrinol. Metab. 5 (2010) 731-743.

[3] C.A. Greenblum, M.A. Rowe, D.F. Neff, J.S. Greenblum, Midlife women: symptoms associated with menopausal transition and early postmenopause and quality of life, Menopause 1 (2013) 22-27.

[4] H.D. Nelson, Menopause, Lancet 9614 (2008) 760-770.

[5] D. Ameratunga, J. Goldin, M. Hickey, Sleep disturbance in menopause, Intern. Med. J. 7 (2012) 742-747.

[6] S.E. Tom, D. Kuh, J.M. Guralnik, G.D. Mishra, Self-reported sleep difficulty during the menopausal transition: results from a prospective cohort study, Menopause 6 (2010) 1128-1135.

[7] H.M. Kravitz, P.A. Ganz, J. Bromberger, L.H. Powell, K. Sutton-Tyrrell, P.M. Meyer, Sleep difficulty in women at midlife: a community survey of sleep and the menopausal transition, Menopause 1 (2003) 19-28.

[8] D.L. Bliwise, Normal aging, in: M.H. Kryger, T. Roth, W.C. Dement (Eds.), Principles and Practice of Sleep Medicine, Saunders, Philadelphia, 1994, pp. 26-39.

[9] L. Lampio, P. Polo-Kantola, O. Polo, T. Kauko, J. Aittokallio, T. Saaresranta, Sleep in midlife women: effects of menopause, vasomotor symptoms, and depressive symptoms, Menopause 11 (2014) 1217-1224.

[10] H.M. Kravitz, X. Zhao, J.T. Bromberger, et al., Sleep disturbance during the menopausal transition in a multi-ethnic community sample of women, Sleep 7 (2008) 979-990.

[11] M.M. Ohayon, Severe hot flashes are associated with chronic insomnia, Arch. Intern. Med. 12 (2006) 1262-1268.
[12] J.P. Brown, L. Gallicchio, J.A. Flaws, J.K. Tracy, Relations among menopausal symptoms, sleep disturbance and depressive symptoms in midlife, Maturitas 2 (2009) 184-189.

[13] R.R. Freedman, T.A. Roehrs, Sleep disturbance in menopause, Menopause 5 (2007) 826-829.

[14] K. Plotkin, Insomnia caused by medical disorders, in: H.P. Attarian, C. Schuman (Eds.), Clinical Handbook of Insomnia, Humana, Totowa, NJ, 2010, pp. 195-208.

[15] L. Lampio, T. Saaresranta, O. Polo, P. Polo-Kantola, Subjective sleep in premenopausal and postmenopausal women during workdays and leisure days: a sleep diary study, Menopause 6 (2013) 655-660.

[16] T. Saaresranta, P. Polo-Kantola, O. Polo, Practical approach to the diagnosis and management of menopausal insomnia, in: H.P. Attarian, M. Viola-Saltzman (Eds.), Sleep Disorders in Women: A Guide to Practical Management, the Netherlands, Humana Press/Springer, New York, 2013, pp. 293-324.

[17] P. Polo-Kantola, R. Erkkola, H. Helenius, K. Irjala, O. Polo, When does estrogen replacement therapy improve sleep quality? Am. J. Obstet. Gynecol. 5 (1998) 1002-1009.

[18] C.M. Morin, P.J. Hauri, C.A. Espie, A.J. Spielman, D.J. Buysse, R.R. Bootzin, Nonpharmacologic treatment of chronic insomnia, an American academy of sleep medicine review, Sleep 8 (1999) 1134-1156.

[19] L. Staner, Comorbidity of insomnia and depression, Sleep Med. Rev. 1 (2010) 35-46.

[20] Y. Dundar, S. Dodd, J. Strobl, A. Boland, R. Dickson, T. Walley, Comparative efficacy of newer hypnotic drugs for the short-term management of insomnia: a systematic review and meta-analysis, Hum. Psychopharmacol. 5 (2004) 305-322.

[21] A.M. Holbrook, R. Crowther, A. Lotter, C. Cheng, D. King, Meta-analysis of benzodiazepine use in the treatment of insomnia, Can. Med. Assoc. J. 2 (2000) 225-233.

[22] M. Partinen, T. Gislason, Basic Nordic Ssleep questionnaire (BNSQ): a quantitated measure of subjective sleep complaints, J. Sleep Res. S1 (1995) $150-155$.

[23] A.T. Beck, C.H. Ward, M. Mendelson, J. Mock, J. Erbaugh, An inventory for measuring depression, Arch. Gen. Psychiatry 56 (1961) 561-571.

[24] E. Vousoura, A.C. Spyropoulou, K.L. Koundi, et al., Vasomotor and depression symptoms may be associated with different sleep disturbance patterns in postmenopausal women, Menopause 10 (2015) 1053-1057.

[25] G.A. Bachmann, Menopausal vasomotor symptoms: a review of causes, effects and evidence-based treatment options, J. Reprod. Med. 3 (2005) 155-165.

[26] J. Hays, J.K. Ockene, R.L. Brunner, et al., Effects of estrogen plus progestin on health-related quality of life, N. Engl. J. Med. 19 (2003) 1839-1854.

[27] C.D. Sarti, A. Chiantera, A. Graziottin, et al., Hormone therapy and sleep quality in women around menopause, Menopause 5 (2005) 545-551.

[28] B. Sivertsen, P. Salo, A. Mykletun, et al., The bidirectional association between depression and insomnia: the HUNT study, Psychosom. Med. 7 (2012) $758-765$.

[29] D. Riemann, Insomnia and comorbid psychiatric disorders, Sleep Med. 4 (2007) 15-20.

[30] E. Toffol, N. Kalleinen, A.S. Urrila, et al., The relationship between mood and sleep in different female reproductive states, BMC Psychiatry 177 (2014), 244X-14-177.

[31] P. Polo-Kantola, A. Laine, M. Aromaa, et al., A population-based survey of sleep disturbances in middle-aged women-associations with health, health related quality of life and health behavior, Maturitas 3 (2014) 255-262.

[32] K. Sarsour, C.M. Morin, K. Foley, A. Kalsekar, J.K. Walsh, Association of insomnia severity and comorbid medical and psychiatric disorders in a health plan-based sample: insomnia severity and comorbidities, Sleep Med. 1 (2010) 69-74.

[33] M.D. Stein, P.D. Friedmann, Disturbed sleep and its relationship to alcohol use, Subst. Abuse 1 (2005) 1-13.

[34] C.M. Yang, C.Y. Hung, H.C. Lee, Stress-related sleep vulnerability and maladaptive sleep beliefs predict insomnia at long-term follow-up, J. Clin. Sleep Med. 9 (2014) 997-1001.

[35] R.A. Bernert, K.A. Merrill, S.R. Braithwaite, K.A. Van Orden, T.E. Joiner Jr., Family life stress and insomnia symptoms in a prospective evaluation of young adults, J. Fam. Psychol. 1 (2007) 58-66.

[36] Q. Xu, C.P. Lang, Examining the relationship between subjective sleep disturbance and menopause: a systematic review and meta-analysis, Menopause 12 (2014) 1301-1318.

[37] S.D. Harlow, M. Gass, J.E. Hall, et al., Executive summary of the Stages of Reproductive Aging Workshop + 10: addressing the unfinished agenda of staging reproductive aging, J. Clin. Endocrinol. Metab. 4 (2012) 1159-1168.

[38] P. Polo-Kantola, Sleep problems in midlife and beyond, Maturitas 3 (2011) 224-232. 